\title{
Intimate Partner Violence: The Effect of Gender and Contextual Factors on Community Perceptions of Harm, and Suggested Victim and Criminal Justice Responses
}

\author{
Susan M. Dennison, PhD \\ Carleen M. Thompson, PhD \\ Griffith University, Queensland, Australia
}

\begin{abstract}
Using a vignette to depict physical violence by an intimate partner, a 2 (perpetrator gender) $\times 2$ (participant gender) $\times 2$ (frequency) $\times 2$ (intent to cause harm) between subjects factorial design was used to examine under what circumstances individuals perceive: an incident should be illegal, the extent of harm, and appropriate victim and criminal justice responses. There were 868 participants from the Brisbane (Australia) community (48.5\% males). The actions of male perpetrators were viewed more seriously and the victims were recommended to seek more forms of assistance when the perpetrator was male. There were few differences in perceptions of violence according to participant gender. The frequency of the violence affected the participant's responses but the intentions of the perpetrator did not. Results are discussed in terms of stereotypes of intimate partner violence (IPV) and the implications for help-seeking behavior by victims.
\end{abstract}

Keywords: physical violence; psychological harm; attributions; repeat violence; gender

I

ntimate partner violence (IPV) involves violence inflicted by an intimate partner towards the other. Intimate partners can be current or former spouses, as well as current or former nonmarital partners. The violence itself falls into four categories: physical, sexual, threats of physical or sexual violence, and psychological/emotional abuse (Saltzman, Fanslow, McMahon, $\&$ Shelley, 2002). Although definitions of IPV are reasonably clear, there are likely to be individual differences in the type of incidents that are considered illegal. Because of the success of any prevention, deterrence or other criminal justice responses depend on the common understanding of what IPV is; it is important to consider how community members (as potential victims, perpetrators, jurors, or critical support networks) perceive IPV. Reddy, Knowles, Mulvany, McMahon, and Freckelton (1997) noted that jurors are likely to have preconceived notions about violence in intimate relationships. Whether such attitudes are then shaped by information specific to a case is not well understood. For example, the gender of the perpetrator and victim, whether violence has occurred previously, and the intentions of the perpetrator, may influence the perceptions of a violent episode and the appropriateness of various victim and criminal justice responses. 
The theoretical domains of attributions of responsibility and blame provide a framework to examine community perceptions of IPV and the factors that contribute to beliefs that an alleged perpetrator should be held accountable and punished. Brewer (1977) argues that attributions of responsibility increase as the relationship between the actions and resulting consequences move through higher levels of responsibility. Such a progression includes those consequences that were not foreseeable to those that were, and finally to those consequences that were intended (Brewer, 1977). However, Brewer also suggests that if the consequences are considered highly probable, then actual intentions may have little impact on the judgments of responsibility. In the case of IPV, victim harm may be seen as a likely consequence of physical violence-rendering the assailant's intentions irrelevant. Similarly, Heider (1958) suggested that a perceiver uses the information available regarding the motivation and the ability of an actor to accomplish an outcome and surrounding situational factors to assign responsibility.

Weiner (1979) extended these theoretical domains to consider the psychological consequences of perceived causality. He argued that an evaluation of behavior would depend on locus of causality, controllability (related to intentionality), and stability. In the context of IPV, a perceiver's attitudes and actions towards an actor would depend on whether they perceived the locus of causality to be internal or external to the actor, the extent to which they perceived the actor to have control over their actions, and whether violence was a stable characteristic of the actor. Intentional harm, rather than accidental harm, and a history of IPV may be taken as the indicators of controllability and stability and, therefore, increase negative perceptions of the actor. It is, therefore, pertinent to combine both an examination of intentions and frequency of violence in a study of perceptions of IPV; yet to date, no studies have systematically manipulated these variables in hypothetical IPV scenarios.

Several studies have investigated the attributions of blame and responsibility in relation to hypothetical IPV scenarios (e.g., Ho \& Venus, 1995; Pavlou \& Knowles, 2001; Reddy et al., 1997), as well as understanding when community members believe a criminal justice response to IPV is warranted (e.g., Herzog, 2007; Sorenson \& Taylor, 2005). Recent studies have questioned assumptions regarding lenient attitudes to male-perpetrated IPV, suggesting a change in modern sociocultural beliefs. However, few studies have examined the effect of both perpetrator and participant gender on the perceptions of IPV (Sorenson \& Taylor, 2005) or the interactions of these characteristics with other contextual factors such as intentions and previous IPV.

\section{GENDER OF PERPETRATOR}

Although IPV is traditionally viewed as a gendered crime, there is some evidence that women are just as likely as men to perpetrate IPV (e.g., Archer, 2000; Moffitt, Caspi, Rutter, \& Silva, 2001), and women are more likely to be injured (Archer, 2000). Several studies that examined the gender of the perpetrator found a greater acceptance of femaleperpetrated violence rather than male-perpetrated violence (e.g., Feather, 1996; Hamel, Desmarais, \& Nicholls, 2007; Harris, 1991; Hilton, Harris, \& Rice, 2003; Simon et al., 2001; Stewart \& Maddren, 1997). In an extensive study of community perceptions of IPV, Sorenson and Taylor (2005) manipulated the characteristics of the perpetrator, victim, and incident in vignettes depicting a heterosexual relationship. The behavior of male perpetrators was considered more wrong, more in need of intervention, and more 
likely to be considered illegal than the same aggressive behavior perpetrated by women (Sorenson \& Taylor, 2005). For example, although participants believed that a slap by a man or a woman delivered to their heterosexual partner should be illegal, they did not believe that any criminal justice response for the woman's actions were appropriate. These findings are consistent with Henning and Feder's (2005) study of the outcomes of prosecutions of domestic violence in a U.S. county. They found that women were more likely to be released on their own recognizance, more likely to have their charges dropped, less likely to be convicted, and if convicted, were likely to receive a lighter sentence than men, even after controlling for other legal and extralegal factors (Henning \& Feder, 2005).

Beyers, Leonard, Mays, and Rosén (2000) have also found that some gender effects are particular to the violent incident itself, such that the sexual abuse of a man by a woman was rated as more abusive by female participants than by male participants, but there were no differences when the man was the perpetrator across types of abuse (emotional, sexual, and physical). Furthermore, Bethke and DeJoy (1993) found that there was no difference in the perceived risk of future violence according to perpetrator gender when the parties were in a serious relationship, but that male perpetrators were perceived to pose a greater risk than female perpetrators in a casual relationship. Further research is required to examine the effect of perpetrator gender on perceptions of the illegality of behavior with respect to contextual factors, as well as whether the appropriateness of various criminal justice sanctions varies according to the perpetrator's gender.

\section{GENDER OF PARTICIPANT}

Findings regarding perceptions of IPV according to the gender of the participant are inconsistent and may be dependent on the perpetrator's gender (e.g., Arias \& Johnson, 1989; Beyers et al., 2000). Feather (1996) reported that women judged a female perpetrator as less deserving of the penalty, had less positive affect about the penalty (i.e., more angry, dissatisfied, disappointed, and displeased), and show more sympathy for the female perpetrator than men. These differences were not replicated when the husband was the perpetrator. Women determined that the offense was more serious than did men when it was perpetrated by the husband. Beyers et al. (2000) also found no significant differences between men and women's perceptions of courtship abuse when the perpetrator was male. Such findings may reflect changes in sociocultural beliefs, whereby both men and women view male-to-female violence as unacceptable (see Archer, 2000; Hamel, et al., 2007; Harris, 1991; Harris, 1994; Taylor \& Mouzous, 2006). Furthermore, Sorenson and Taylor (2005) found few differences in perceptions of an extensive range of IPV scenarios according to participant gender. Clearly, the possible effect of participant gender and its interaction with factors such as perpetrator gender require further investigation.

\section{FREQUENCY OF VIOLENCE}

A history of physical violence is likely to impact the perceptions of IPV because according to Weiner (1979), the stability of behavior is a key consideration in the evaluations of 
behavior. Yet, the effect of the frequency of any form of IPV on community perceptions of IPV has not been adequately addressed. Much of the research use hypothetical scenarios in which a history of physical or verbal abuse is present (e.g., Feather, 1996; Ho \& Venus, 1995; Lane \& Knowles, 2000). In a study whereby frequency was manipulated, Sorenson and Taylor (2005) found that hypothetical incidents of male-perpetrated IPV involving the incident was more likely to be reported as illegal if it was the fifth time the incident occurred as opposed to the first time. Furthermore, the frequency of behavior influenced whether participants believed that a restraining order should be issued.

Follingstad and DeHart (2000) conducted a study of psychologists' perceptions of psychological abuse by a husband toward a wife. Items relating to the frequency and the duration of abuse were more influential in the perceptions of psychological abuse than items relating to the perpetrator's intentions or perceptions of harm to the victim. The authors suggest that a pattern of domination may be more important than the perpetrator's intentions to harm or control his wife.

\section{INTENT TO CAUSE HARM}

A fundamental tenet of most criminal laws is the element of intent to cause harm. Intentionality is also thought to be an important feature of attributions of responsibility (e.g., Brewer, 1977; Heider, 1958). In addition, the role of intent in IPV has not been subjected to scrutiny despite some legal conceptualizations distinguishing between the intentionality of violence (Mears, 2003). Few researchers have incorporated intent (or controllability) into studies of IPV perceptions. Follingstad and DeHart (2000) reported that using a sample of psychologists, the frequency and the duration of abuse were more influential in identifying psychological abuse than intentions or the perceptions of harm by the victim. However, Follingstad, Helff, Binford, Runge, and White (2004) subsequently found that lay persons were more reliant on information regarding the perpetrator's intentions than the frequency of the behavior. Further research is required to examine whether an intent distinguishes the perceptions of normal relational disputes and accidental harm from IPV and how this factor interacts with both the gender of the perpetrator and participant as well as the frequency of violence. At present, it is unclear whether harm resulting from an IPV incident is such an obvious consequence that an intent to cause harm becomes irrelevant, as posited by Brewer (1977), or whether an intent to do harm increases negative perceptions of the perpetrator (e.g., Brewer, 1977; Weiner, 1979).

\section{THE CURRENT STUDY}

The present research aims to examine the contextual and participant factors that impact the perceptions of physical violence within an intimate relationship. The experimental design is a 2 (perpetrator gender) $\times 2$ (participant gender) $\times 2$ (frequency of violence) $\times$ 2 (perpetrator's intentions) between subjects factorial design. The dependent variables are the circumstances under which community members believe that an incident should be illegal, whether the perpetrator has a reasonable excuse for his or her actions, the extent of physical and psychological harm inflicted on the victim, whether a similar incident is likely to occur again, and the appropriate victim and criminal justice responses. There are four key hypotheses: 


\section{Hypothesis 1: Gender of Perpetrator}

Given (a) the general findings that there is greater acceptance of female-perpetrated IPV rather than male-perpetrated IPV, and (b) the specific findings of Sorenson and Taylor (2005) that the behavior of male perpetrators is more likely to be considered illegal and in need of intervention, it is hypothesized that: When the perpetrator is male rather than female, the incident will more often be deemed illegal, the perpetrator will be judged less likely to have a reasonable excuse, greater physical and psychological harm to the victim will be perceived to occur, he will be judged more likely to repeat the behavior, appropriate victim responses will be more likely to include seeking external support and criminal justice intervention, and more serious punishments will be recommended.

\section{Hypothesis 2: Participant Gender}

Given the inconsistent findings in the previous research and the interactions found between participant and perpetrator gender (Arias \& Johnson, 1989; Beyers et al., 2000), no main effects for participant gender are proposed. Rather, it is tentatively hypothesized that: There will be an interaction between participant's and perpetrator's gender. That is, women will perceive that a male perpetrator caused greater physical and psychological harm and would be more likely to repeat the behavior than the female perpetrator. There are no differences hypothesized for male participants.

\section{Hypothesis 3: Frequency of Violence}

Based on the effect of frequency found by Sorenson and Taylor (2005) and the role of stability purported by Weiner (1979), it is hypothesized that: When the vignette contains information indicating that violence has occurred before, as opposed to a single episode, the participants will be more likely to decide that the behavior is illegal, that the perpetrator has a less reasonable excuse, that the violence led to greater psychological (but not physical) harm, that violence will be more likely to be repeated, that appropriate victim's responses will be more likely to include seeking external support and criminal justice intervention, and that more serious punishments will be recommended.

\section{Hypothesis 4: Intent to Cause Harm}

Given that this variable has not been closely examined in IPV research, tentative hypotheses are offered based on (a) Heider's (1958) and Weiner's (1979) theories of attribution in relation to intentionality, and (b) the findings by Follingstad and colleagues (2004) that lay persons rely more heavily on information regarding intentions rather than the frequency of violence. It is therefore hypothesized that: When there is explicit intent to cause harm, as opposed to no explicit intent, participants will be more likely to identify the behavior as illegal, indicate that the perpetrator has a less reasonable excuse for the violence, that the victim suffered more psychological and physical harm, that violence is more likely to be repeated, and that more serious punishments should be proscribed. There are no hypothesized effects for victim responses. There are no interactions hypothesized between intent and frequency because it is possible that prior violence will cancel out any effect of intent (as per Brewer, 1977), rather than lead to more negative attitudes when both explicit intent and prior violence are present. Nevertheless, interactions will be examined. 


\section{METHOD}

\section{Participants}

The sample was composed of 868 participants from the Brisbane (Queensland, Australia) community ( $48.5 \%$ were males and $51.5 \%$ were females). The ages of participants ranged from 18 to 83 years old. The mean age of males was 40.41 years old $(S D=16.17)$, and the mean age for females was 40.28 years old $(S D=14.15)$. The sample was reasonably well educated; only $4 \%$ of the participants had not completed high school, $35 \%$ had completed high school, $31 \%$ had completed a technical and further education (TAFE) or university certificate or diploma, $20 \%$ had completed an undergraduate degree, and $10 \%$ held a postgraduate degree ( $n=52$, missing). Most of the participants were married or living in a de facto relationship (74\%), $22 \%$ were single or have never been married, $3 \%$ were divorced or separated, and $1 \%$ were widowed $(n=6$, missing). Participants were treated in accordance with the ethical guidelines of the National Health and Medical Research Council.

\section{Materials}

Participants were given a one-paragraph vignette depicting a person engaging in behavior that could be perceived as a primarily physically violent form of IPV in a heterosexual couple. The vignettes varied according to the manipulation of the gender of the perpetrator, intent to cause physical injury, and the frequency of the violence. ${ }^{1}$ The vignette as mentioned in the subsequent text depicts a male perpetrator/female victim and contains the manipulation of no explicit evidence of intent in italics and explicit intent enclosed in parentheses, followed by the manipulation of frequency with the single episode in italics and repeat episode enclosed in parentheses.

Robert and Jenny have been married for 1 year. Jenny usually gets home from work around 6 p.m. but this Thursday evening, she does not arrive home until 11 p.m. Robert is furious that Jenny didn't call to say that she would be home late and has been wondering where she is. He called her office phone but she did not answer. When Jenny walks in the door at home, Robert tells her how upset he is. Jenny says that she has been in a meeting that ran late and she didn't have a handy phone to call him. He says that she is taking the marriage for granted and not respecting him (He says that she is taking the marriage for granted and that he will teach her a lesson about respect). With that, he picks up her dinner that he has been keeping warm and throws the plate at Jenny. The plate hits her on the side of the head and cuts her above the ear. The food flies all over her. Blood runs down the side of her head and neck. Robert is instantly distressed about what he has done. He didn't mean to lose his temper and he has never hurt Jenny before (he has hurt Jenny a couple of times before but he promised her it wouldn't happen again).

Participants completed a questionnaire on their perceptions of the events, including: (a) whether the behavior should be illegal (i.e., informal opinions on whether it should be prosecuted: No/Yes); (b) the extent to which participants believed that the perpetrator had a reasonable excuse for his or her actions; (c) the extent of physical harm inflicted on the victim; (d) the extent of psychological or emotional harm inflicted on the victim; and (e) how likely it was that the perpetrator would do the same thing again. Questions 2-5 were answered on a 9-point Likert-type scale. Question 2 answers ranged from 1 (not at all reasonable) to 9 (very reasonable). Questions 3 and 4 answers ranged from 1 (no harm at all) to 9 (severe harm). Questions 5 and 6 answers ranged from 1 (not at all likely) 
to 9 (extremely likely). Additional questions included (f) how should the victim respond to the behavior? (12 items were developed by the researchers, participants could check as many items as relevant) and (g) what type of sanctions would be appropriate for the perpetrator if he or she went to court and was convicted? (6 items ranging from no conviction recorded to prison sentence). Questions were also included to conduct manipulation checks.

\section{Procedure}

Two methods were used to recruit participants. First, a random selection of community members from the Brisbane metropolitan electoral rolls were telephoned and invited to participate in the research. In Australia, all citizens aged 18 years and older are required to vote; therefore, with few exceptions, the electoral rolls identify all adults living within each district. Individuals with a listed telephone number were selected using random digits. Willing participants were posted with the research materials (approximately 1,240 research packages were posted). Using this method, 664 completed questionnaires were returned (response rate was 54\%). The second method involved recruiting members of the community from two university campuses (approximately 1,050 research packages were distributed) to increase the number of young adults in the sample. General community members were recruited, as well as students, as approximately half of the questionnaires distributed in this manner were on a weekend when the university was open to prospective students and their parents/ family members. Using this method only 204 completed questionnaires were returned (response rate was 19\%).

Participants that were contacted through the electoral rolls were sent with reminder letters a week after the materials were posted, potentially accounting for the higher response rate using this recruitment method. The combined response rate of the two methods was $38 \%(N=868)$. Dependent variables did not significantly differ across the two recruitment methods. Participant numbers ranged from 50 to 62 across the 16 conditions.

\section{RESULTS}

Results were analyzed using the Statistical Package for the Social Sciences (SPSS) 15.0 for Microsoft Windows. Frequencies in some analyses do not add up to 868 because some participants failed to respond to certain questions. Unless otherwise reported, significance levels for tests were set at .05 .

\section{Manipulation Checks}

The manipulation of the intentions of the perpetrator was successful, although a little weak, whereby participants in the explicit intent condition reported that the perpetrator was more likely to have intended to cause physical harm to the victim $(M=4.38$, $S D=2.45)$ than participants who received a vignette with no explicit intent $(M=3.72$, $S D=2.23), t(854.82)=-4.19, p<.001(d=0.28)$. The manipulation of frequency was successful, whereby more participants in the repeat episode condition reported that the perpetrator had engaged in similar behavior previously (96\%) than participants in the single-episode condition (17\%), $X^{2}(1)=558.50, p<.001$, Cramer's V $=0.80$. 


\section{Is Behavior Illegal?}

Two-thirds of the participants reported that the behavior depicted in the vignettes should be illegal, whereas $34 \%$ did not. A forward stepwise logistic regression was conducted to examine which variables were significant in identifying behavior as illegal. The second model was significant, $\chi^{2}(2, N=855)=71.12, p<.001$. However, the variance accounted for was small (Nagelkerke $R^{2}=.11$ ). Although this model correctly classified $81 \%$ of the participants who considered the behavior as illegal, only $39 \%$ of the participants who considered the behavior legal were correctly classified. The overall classification accuracy of $67 \%$ was similar to that attained in the constant only model $(66 \%)$.

The results revealed that frequency had a significant main effect on responses with $71 \%$ of participants indicating that the behavior was illegal in the repeat episode condition, compared with $62 \%$ in the single-episode condition $(O R=.65$ [CI $=.48-.87], p<.004)$. Furthermore, significantly more participants said that the behavior was illegal when the vignette depicted a male perpetrator and female victim (79\%) compared to female perpetrator and male victim $(54 \% ; O R=3.27[\mathrm{CI}=2.42-4.43], p<.001)$.

\section{Reasonable Excuse}

A four-way factorial analysis of variance (ANOVA) was conducted to examine the impact of perpetrator gender, participant gender, frequency, and intent on perceptions of the extent to which the perpetrator had a reasonable excuse for his or her behavior. There was a main effect of perpetrator gender, $F(1,849)=85.58, p<.001$, partial $\eta^{2}=$ .09 and a main effect of participant gender, $F(1,849)=8.86, p=.003$, partial $\eta^{2}=.01$. However, there was also a significant interaction between perpetrator gender and participant gender, $F(1,849)=4.25, p=.040$, partial $\eta^{2}=.01$. Analysis of simple effects revealed that there was only a significant difference between men and women when the perpetrator was female. Men reported that the female perpetrator had a more reasonable excuse $(M=3.42, S D=2.13)$ than did women $(M=2.82, S D=1.85), t(421.82)=$ $3.10, p=.002$.

\section{Extent of Physical Harm}

A four-way factorial ANOVA was conducted to examine the impact of perpetrator gender, participant gender, frequency, and intent on perceptions of the extent to which the perpetrator inflicted physical harm on the victim. There was a main effect of frequency, with participants in the repeat-episode condition indicating that the extent of physical harm to the victim was higher $(M=5.96, S D=1.78)$ than participants in the single-episode condition $(M=5.58, S D=1.88), F(1,850)=9.86, p=.002$, partial $\eta^{2}=.01$. There was also main effect of perpetrator gender, $F(1,850)=85.36, p<.001$, partial $\eta^{2}=.09$, and an interaction between perpetrator gender and participant gender, $F(1,850)=4.44, p=.035$, partial $\eta^{2}=.01$. Analysis of simple effects revealed that when the perpetrator was female, women perceived a greater degree of physical harm to the victim $(M=5.44, S D=1.71)$ compared to men $(M=5.00, S D=1.78), t(433)=-2.59, p=.01$.

\section{Extent of Psychological or Emotional Harm}

A four-way factorial ANOVA was conducted to examine the impact of perpetrator gender, participant gender, frequency, and intent on perceptions of the extent to which 
the perpetrator inflicted psychological or emotional harm on the victim. There were main effects for perpetrator gender, participant gender, and frequency. Participants perceived more psychological or emotional harm to the victim when the perpetrator was male $(M=7.64, S D=1.43)$ rather than female $(M=6.04, S D=2.04), F(1,849)=$ $180.99, p<.001$, partial $\eta^{2}=.18$. Women perceived a higher level of psychological or emotional harm to the victim $(M=7.07, S D=1.86)$ than men $(M=6.59, S D=$ 1.99), $F(1,833)=14.97, p<.001$, partial $\eta^{2}=.02$. Participants in the repeat-episode condition indicated that the extent of psychological or emotional harm to the victim was higher $(M=7.14, S D=1.76)$ than participants in the single-episode condition $(M=6.52, S D=2.06), F(1,833)=26.10, p<.001$, partial $\eta^{2}=.03$. There was also a significant three-way interaction between perpetrator gender, frequency, and intent $(p=.04)$. However, the analysis of simple effects did not reveal any meaningful differences and given the small effect size (partial $\eta^{2}=.005$ ), the interaction is not discussed further.

\section{Likelihood of Repeat Behavior}

A four-way factorial ANOVA was conducted to examine the effect of perpetrator gender, participant gender, frequency, and intent on perceptions of the extent to which the perpetrator was likely to repeat his or her violent behavior toward the victim. There were main effects of perpetrator gender, participant gender, and frequency. Participants perceived that the male perpetrator was more likely to engage in the behavior again $(M=6.68, S D=$ 2.27) compared to the female perpetrator $(M=5.79, S D=2.45), F(1,832)=150.90, p<$ .001 , partial $\eta^{2}=.05$. Women perceived that the perpetrator was more likely to engage in the violent behavior again $(M=6.52, S D=2.39)$ than did men $(M=5.92, S D=2.37)$, $F(1,832)=21.11, p<.001$, partial $\eta^{2}=.02$. Participants in the repeat-episode condition indicated that the perpetrator was more likely to engage in the behavior again $(M=7.55$, $S D=1.64)$ than participants in the single-episode condition $(M=4.87, S D=2.30)$, $F(1,832)=404.33, p<.001$, partial $\eta^{2}=.33$.

\section{Appropriate Victim Response}

Community members were requested to indicate which of 12 possible victim responses were most appropriate under the circumstances (participants could check more than one response). Given the significant findings pertaining to perpetrator gender, participant gender, and frequency of violence, a series of two-way Chi-squares were performed to examine differences in responses for each of these independent variables. Using a Bonferroni correction, alpha was reduced to .004 for each set of the 12 comparisons. Results are reported in Table 1. Appropriate victim responses differed according to perpetrator gender for all responses except for ignoring the behavior and seeking counseling. Men and women only differed significantly on two possible victim responses, whereas recommended responses according to the frequency of the violence differed significantly in 8 out of the 12 categories.

\section{Penalties}

Participants who responded that the behavior should be illegal were requested to indicate which penalties, from six options, they believed would be appropriate for the perpetrator. Participants could select multiple options. The results are presented in Table 2. Most of 
TABLE 1. Recommended Victim Responses According to Perpetrator Gender, Participant Gender, and Frequency of Violence

\begin{tabular}{|c|c|c|c|c|c|c|}
\hline \multirow[b]{2}{*}{ Victim Response } & \multicolumn{2}{|c|}{ Perpetrator Gender } & \multicolumn{2}{|c|}{ Participant Gender } & \multicolumn{2}{|c|}{ Frequency } \\
\hline & Male \% & Female $\%$ & Male $\%$ & Female $\%$ & Single $\%$ & Repeat $\%$ \\
\hline Ignore behavior & 2.3 & 3.4 & 3.1 & 2.7 & 4.2 & 1.6 \\
\hline $\begin{array}{l}\text { Part of being in } \\
\text { a relationship }\end{array}$ & 2.1 & 9.9 & 8.6 & 3.6 & 8.9 & 3.2 \\
\hline $\begin{array}{l}\text { Get upset then } \\
\text { forget about it }\end{array}$ & 4.9 & 18.8 & 15.4 & 8.5 & 17.3 & 6.6 \\
\hline $\begin{array}{l}\text { Consult family/ } \\
\text { friends }\end{array}$ & 53.4 & 29.6 & 43.2 & 39.7 & 35.4 & 47.3 \\
\hline Call police & 32.0 & 6.4 & 17.8 & 20.4 & 13.6 & 24.5 \\
\hline $\begin{array}{l}\text { Press charges } \\
\text { against partner }\end{array}$ & 20.2 & 4.8 & 10.9 & 13.9 & 7.5 & 17.3 \\
\hline Seek counseling & 73.5 & 71.1 & 67.9 & 76.5 & 67.9 & 76.6 \\
\hline $\begin{array}{l}\text { Tell partner to } \\
\text { go to counseling }\end{array}$ & 39.4 & 23.2 & 28.5 & 33.9 & 22.5 & 39.8 \\
\hline $\begin{array}{l}\text { Break off } \\
\text { relationship }\end{array}$ & 24.1 & 8.5 & 15.2 & 17.3 & 10.5 & 21.8 \\
\hline $\begin{array}{l}\text { Threaten to } \\
\text { call police if it } \\
\text { happens again }\end{array}$ & 35.0 & 16.7 & 23.3 & 28.3 & 28.1 & 23.6 \\
\hline $\begin{array}{l}\text { Threaten to } \\
\text { press charges } \\
\text { if it happens } \\
\text { again }\end{array}$ & 29.7 & 13.3 & 18.3 & 24.4 & 24.6 & 18.4 \\
\hline $\begin{array}{l}\text { Threaten to end } \\
\text { relationship if } \\
\text { it happens again }\end{array}$ & 48.5 & 33.0 & 38.2 & 43.0 & 41.9 & 39.5 \\
\hline
\end{tabular}

Note. $N=867, d f=1$; Percentages in bold denote significant differences at $p<.004$.

the participants responded that the perpetrator should be placed on a community-based order (whereby a sentence is served in the community and may contain certain reporting, work, and treatment requirements). Few participants believed the perpetrator should serve a prison sentence.

A series of two-way Chi-square tests were conducted to examine whether there were any differences in recommended penalties according to perpetrator gender, participant gender, and frequency. Using a Bonferroni correction, alpha was reduced to .008 for the six comparisons on each of the independent variables. There were three significant differences in recommended penalties according to perpetrator gender. Significantly, more participants recommended that no conviction should be recorded when the perpetrator was female 
TABLE 2. Suggested Penalties for Those Who Said Behavior Was Illegal

\begin{tabular}{lclr}
\hline Type of Penalty & $\%$ & \multicolumn{1}{c}{ Length/Amount } & $\%$ \\
\hline No conviction recorded & 18.5 & & \\
Fine & 14.0 & Less than $\$ 500$ & 22.8 \\
& & $\$ 500-\$ 1,000$ & 43.0 \\
& & Greater than $\$ 1,000$ & 21.5 \\
& & Cost of medical and court costs & 6.3 \\
\hline Community service & 17.8 & Less than 6 months & 43.0 \\
& & 6-12 months & 41.0 \\
& & 12-24 months & 5.0 \\
& & Greater than 24 months & 0.0 \\
\hline Community-based order & 82.2 & Less than 6 months & 21.8 \\
& & 6-12 months & 60.9 \\
& & 12-24 months & 5.8 \\
& & Greater than 24 months & 0.4 \\
& & Receive counselling as long as & 2.8 \\
\hline Suspended sentence & 11.9 & needed & 6.0 \\
& & Less than 6 months & 64.2 \\
& & 6-12 months & 22.4 \\
& & Greater than 24 months & 4.5 \\
\hline Prison sentence & 4.8 & Less than 6 months & 22.2 \\
& & 6-12 months & 51.9 \\
& & 12-24 months & 3.7 \\
& & Greater than 24 months & 14.8 \\
\hline & & &
\end{tabular}

Note. $N=563$.

(30\%) compared to when the perpetrator was male (10\%), $\chi^{2}(1, N=563)=36.95, p<$ .001 , Cramer's $\mathrm{V}=0.26$. Whereas significantly more participants recommended a suspended sentence when the perpetrator was male $(17 \%)$ as opposed to female $(5 \%), \chi^{2}(1$, $N=563)=16.57, p<.001$, Cramer's $\mathrm{V}=0.17$. Participants were also significantly more likely to recommend a prison sentence for the male perpetrator (7\%) compared to the female perpetrator $(2 \%), \chi^{2}(1, N=563)=7.96, p<.008$, Cramer's $\mathrm{V}=0.12$.

There was only one significant difference according to participant gender. Significantly, more women $(89 \%)$ than men $(75 \%)$ recommended a community-based order for the perpetrator, $\chi^{2}(1, N=563)=18.52, p<.001$, Cramer's $\mathrm{V}=0.18$. There were three significant findings for frequency. Significantly, more participants recommended that no conviction should be recorded in the single-episode condition (25\%) compared with the 
repeat-episode condition (13\%), $\chi^{2}(1, N=563)=14.29, p<.001$, Cramer's V $=0.16$. Significantly, more participants recommended a community-based order in the repeat episode condition (89\%) compared with the single-episode condition $(74 \%), \chi^{2}(1, N=$ $563)=19.94, p<.001$, Cramer's $V=0.19$. Finally, significantly more participants recommended a prison sentence in the repeat-episode condition (7\%) compared with the single-episode condition $(2 \%), \chi^{2}(1, N=563)=8.52, p<.005$, Cramer's V $=0.12$.

\section{DISCUSSION}

This research examined the conditions under which community members believe that violence within a heterosexual intimate relationship should be illegal. The study also examined how community members perceive harm, further risk to the victim, and appropriate victim and criminal justice responses in such situations. Particular strengths of the study included the manipulation of both perpetrator and participant gender, that the sample composed approximately the equal numbers of men and women, and that most of the sample was drawn randomly from the community as opposed to comprising solely a student sample. The study also investigated the effect of frequency of violence at lower levels than previous research and the effect of perpetrator intentions on perceptions, which has not been systematically manipulated in previous IPV research. Four hypotheses were proposed to test the effect of perpetrator gender, participant gender, frequency, and intent.

General support existed for the first hypothesis relating to perpetrator gender. Consistent with the previous research (e.g., Arias \& Johnson, 1989; Bethke \& DeJoy, 1993; Feather, 1996; Hamel et al., 2007; Harris, 1991; Hilton et al., 2003; Simon et al., 2001; Stewart \& Maddren, 1997), participants were more accepting of female-perpetrated violence than male-perpetrated violence. Specifically, participants were more likely to identify the behavior of a male perpetrator as illegal and recommend more severe penalties. Although community members appear to have common understandings of male-perpetrated IPV, there appears to be considerably more ambiguity in the perceptions of female-perpetrated IPV. The sample was reasonably evenly divided whether the conduct of the female perpetrator was illegal. Consistent with Beyers et al. (2000), it appeared that men in this study were more likely than women to be lenient with the female perpetrator. Furthermore, even for those participants who did believe that the conduct was illegal, three times as many participants recommended that no conviction should be recorded for the female perpetrator compared to the male perpetrator. These findings are consistent with those of Sorenson and Taylor (2005) who found that the behavior of a male perpetrator was more often considered illegal and more lenient criminal justice responses were necessary for female perpetrators. Sorenson and Taylor also reported greater variance in perceptions of female perpetrators' behavior, leading them to suggest that social norms for female-to-male violence were less clear than male-to-female violence. Together, these findings raise concerns as to how jurors may perceive female-perpetrated IPV and similarly, whether male victims of female-perpetrated IPV will seek and receive appropriate assistance.

Bethke and DeJoy (1993) found no difference in the perceived risk of future violence according to perpetrator gender when the parties were in a serious relationship. However, in this study depicting a married couple, participants believed that the male perpetrator was more likely than the female perpetrator to repeat the violence again. When the perpetrator was male rather than female, participants were also more likely to recommend that the victim seek external supports, threaten to or actually terminate the relationship, and threaten 
to or actually call the police or press charges. However, it should be noted that even in the male-perpetrator conditions, only one-third of the participants believed that the victim should call the police. It appears that participants are seeking to ensure that the violence does not occur again but are reluctant to have criminal justice involvement. There was a tendency for participants to recommend the victim to use noncriminal justice responses such as consulting friends and family, seek counselling, and terminate the relationship. Further research is required to examine why community members do not believe victims should call the police, even when they have identified the behavior as illegal.

The second hypothesis that there would be an interaction between the participant's and perpetrator's gender was only partially supported, and these interactions have been discussed previously. However, there were also main effects for participant gender that were not hypothesized. Women perceived a greater level of psychological or emotional harm to the victim than did men, whereas there was no main effect for participant gender in relation to physical harm. The lack of effect for physical harm may be caused by the description of harm in the vignette, where the victim was bleeding as a consequence of the incident, indicating at least some level of harm for both male and female victims. Future research could explore whether there is an effect of participant gender on perceptions of physical harm when the resulting harm is not described.

Women were more likely than men to believe that the perpetrator would engage in the violent behavior again. They were also less likely than men to suggest that the victim accept that the behavior is just part of being in a relationship or to simply get upset and then forget about the incident. However, in relation to recommended penalties, men and women only differed significantly on one of the possible penalties, with more women than men recommending a community-based order. Although the results in relation to participant gender generally support the notion that there has been a shift in sociocultural beliefs, both men and women have been viewing physical IPV as serious and unacceptable (e.g., Archer, 2000; Hamel, et al., 2007; Harris, 1991; Harris, 1994; Sorenson \& Taylor, 2005; Taylor \& Mouzous, 1996)

The third hypothesis predicted that on all measures, except for physical harm, the behavior would be perceived more negatively in the repeat-episode condition compared with the single-episode condition. There was general support for this hypothesis. Participants were more likely to identify the behavior as illegal, believe that the perpetrator had caused greater psychological harm and was more likely to repeat the behavior, that the victim should seek external and criminal justice support, and recommend more serious penalties when the violence had occurred previously as opposed to being the first time. However, there was also a main effect for physical harm that was not hypothesized, with participants indicating that the resulting physical harm was greater in the repeatepisode condition versus single-episode condition. This was a surprising finding given that the physical consequences to the victim were identical in the vignettes. However, the effect size was small. Furthermore, contrary to the hypothesis, frequency had no effect on whether the perpetrator was perceived to have a reasonable excuse for the behavior.

The findings are consistent with those of Sorenson and Taylor (2005) who reported similar results comparing first time violence with violence occurring for the fifth time. This study demonstrated that perceptions of the seriousness of the behavior also shift at lower frequencies, that is, from the first to third time that the violence occurs. Participants' views of the IPV may relate to their beliefs whether the violence is likely to happen again. When it occurred for the first time, the participants were undecided whether the violence would be repeated. However, when the IPV occurred for the third time, the perceived 
likelihood of it being repeated rose to a considerably high level. Therefore, participants may be prepared to give the benefit of the doubt in the first instance, but should see an inevitable pattern of violence when it occurs three times. These findings have implications for any campaigns aimed at encouraging victims to seek help when IPV first occurs in terms of understanding the ambiguity that individuals may have in defining the behavior in a single versus repeat episode of violence.

Finally, contrary to the fourth hypothesis, there was no effect of the intentions of the perpetrator on participants' perceptions of the behavior or did intent interact with frequency. These findings may be caused by the weak, although significant, manipulation of intent. Alternatively, it may indicate that contrary to the findings of Follingstad et al. (2004) but consistent with those of Follingstad and DeHart (2000), the actions and harm caused by the perpetrator are more relevant than the actual intentions to cause harm. This also accords with Brewer's (1977) assertion that when consequences are considered highly probable, the intentions may carry little weight in judgments of responsibility. In this study, the participants may have determined that the probability of harm arising from throwing a dinner plate at someone was reasonably high. As such, the actor's intentions may have been irrelevant because the actions themselves and the likelihood of harm were unacceptable. It is recommended that future research examine the possible effect of intent on perceptions of IPV with a stronger manipulation of intent.

Additional limitations of the study include the generalizability of findings across both vignette studies of IPV and communities more generally. As studies of IPV use different vignettes, the effects of independent variables must be considered in light of the overall vignette and the context of the depicted behavior. For example, in this study, a history of IPV significantly affected the perceptions of the event. Where a history of IPV is included in vignette designs, it would be useful for researchers to specify or quantify this history where possible, to enable findings to be compared across studies. Furthermore, this study composed a participant sample drawn from the Brisbane (Queensland, Australia) community. Although it is not anticipated that this sample differs markedly in their attitudes from any other urban city in Australia or cities in the United States or in the United Kingdom, a measure of attitudes towards IPV or gender-role attitudes would have facilitated a better understanding of the generalizability of the results. In addition, the proportion of participants who are in relationships was higher in this study than in the geographical area of Brisbane where this study was conducted (e.g., $22 \%$ vs. $35 \%$ single, $3 \%$ vs. $11 \%$ divorced or separated, $1 \%$ vs. $5 \%$ widowed, and $74 \%$ married or de facto vs. $48 \%$ married in a sample and 2006 Census, respectively; Australian Bureau of Statistics, 2007). It is possible that individuals in relationships view IPV differently compared to those who are not in relationships, particularly if they give consideration to the financial consequences of leaving a violent partner or the impact on their children (e.g., Logan, Cole, Shannon, \& Walker, 2007; Logan, Shannon, \& Walker, 2005; Walker, Logan, Jordan, \& Campbell, 2004). Future research could examine whether the participants' relationship status affects perceptions of, and responses to, IPV.

\section{CONCLUSION}

The key finding in this research was that the gender of the perpetrator appeared to be the most influential variable in perceptions of IPV as demonstrated by the number of significant findings and the effect sizes. The actions of male perpetrators were viewed 
more seriously than female perpetrators, and victims were recommended to take more actions involving seeking external supports, ending the relationship, and seeking criminal justice responses when the perpetrator was male. A shift in sociocultural beliefs regarding male-perpetrated IPV may explain the current findings, but such shift does not appear to have been generalized to all IPV. That the victimization of a male by a female perpetrator may not be taken as seriously as male-perpetrated IPV in terms of both physical and psychological abuse warrants further investigation, particularly with samples that might be called upon to support or assist the victims of IPV. A history of prior violence was also a significant factor in determining whether the behavior was illegal, caused harm, and appropriate victim and criminal justice responses. The most common recommended victim response across all conditions was for the victim to seek counselling. Even though almost three quarters of participants in the repeat-violence condition believed that the actions of the perpetrator were illegal, only a quarter of participants recommended that the victim call the police. Further research should be conducted to examine the apparent inconsistencies between community members' perceptions of behavior as illegal and their reluctance to recommend the use of the criminal law to respond to the violence.

\section{NOTE}

1. In the original design, the participants were requested to read the vignette as if they were either the perpetrator in the scenario, the victim, or the independent observer. In the perpetrator scenarios, male participants received a vignette that depicted a male perpetrator/female victim whereas female participants received a vignette that depicted a female perpetrator/male victim. The opposite occurred in the victim scenarios. In the observer condition, a group of male participants received a vignette depicting a female perpetrator/male victim and another group received a vignette depicting a male perpetrator/female victim. The same vignettes were also delivered to female participants in the observer conditions. When manipulation checks were conducted, it was apparent that the manipulation of perspective was weak and only partially successful. The manipulation of the perpetrator's conditions was successful for female participants but not for male participants. The manipulation of the victim conditions was successful. However, attempting to place participants as impartial observers was not successful. When participants read a scenario where they were in the same sex as the victim, they identified more with the victim than the perpetrator. Initial analyses of results revealed that any significant main effects or interactions for the perspective variable were driven by the gender of the perpetrator and victim rather than perspective. Therefore, this variable was collapsed and will not be reported further in this article.

\section{REFERENCES}

Archer, J. (2000). Sex differences in aggression between heterosexual partners: A meta-analytic review. Psychological Bulletin, 126(5), 651-680.

Arias, I., \& Johnson, P. (1989). Evaluations of physical aggression among intimate dyads. Journal of Interpersonal Violence, 4(3), 298-307.

Australian Bureau of Statistics. (2007). 2006 Census of population and housing: Media releases and fact sheets. Commonwealth of Australia: Author.

Bethke, T. M., \& DeJoy, D. M. (1993). An experimental study of factors influencing the acceptability of dating violence. Journal of Interpersonal Violence, 8(1), 36-51.

Beyers, J. M., Leonard, J. M., Mays, V. K., \& Rosén, L. A. (2000). Gender differences in the perception of courtship abuse. Journal of Interpersonal Violence, 15(5), 451-466. 
Brewer, M. B. (1977). An information-processing approach to attribution of responsibility. Journal of Experimental Social Psychology, 13, 58-69.

Feather, N. T. (1996). Domestic violence, gender, and perceptions of justice. Sex Roles, 35(7/8), $507-519$.

Follingstad, D. R., \& DeHart, D. D. (2000). Defining psychological abuse of husbands toward wives: Contexts, behaviors, and typologies. Journal of Interpersonal Violence, 15(9), 891-920.

Follingstad, D. R., Helff, C. M., Binford, R. V., Runge, M. M., \& White, J. D. (2004). Lay persons' versus psychologists' judgements of psychologically aggressive actions by a husband and wife. Journal of Interpersonal Violence, 19(8), 916-942.

Hamel, J., Desmarais, S. L., \& Nicholls, T. L. (2007). Perceptions of motives in intimate partner violence: Expressive versus coercive violence. Violence and Victims, 22(5), 563-576.

Harris, M. B. (1991). Effects of sex of aggressor, sex of target, and relationship on evaluations of physical aggression. Journal of Interpersonal Violence, 6(2), 174-186.

Harris, M. B. (1994). Gender of subject and target as mediators of aggression. Journal of Applied Social Psychology, 24(5), 453-471.

Heider, F. (1958). The psychology of interpersonal relations. New York: Wiley.

Henning, K., \& Feder, L. (2005). Criminal prosecution of domestic violence offenses: An investigation of factors predictive of court outcomes. Criminal Justice and Behavior, 32(6), 612-642.

Herzog, S. (2007). An empirical test of feminist theory and research: The effect of heterogeneous gender-role attitudes on perceptions of intimate partner violence. Feminist Criminology, 2(3), 223-244.

Hilton, N. Z., Harris, G. T., \& Rice, M. E. (2003). Adolescents' perceptions of the seriousness of sexual aggression: Influence of gender, traditional attitudes, and self-reported experience. Sexual Abuse, 15(3), 201-214.

Ho, R., \& Venus, M. (1995). Reactions to a battered woman who kills her abusive spouse: An attributional analysis. Australian Journal of Psychology, 47(3), 153-159.

Lane, B., \& Knowles, A. (2000). Community attitudes to domestic violence: Attributions of responsibility, and suggested punishments related to alcohol consumption and level of violence. Psychiatry, Psychology, and Law, 7(1), 51-58.

Logan, T. K., Cole, J., Shannon, L., \& Walker, R. (2007). Relationship characteristics and protective orders among a diverse sample of women. Journal of Family Violence, 22(4), 237-246.

Logan, T. K., Shannon, L., \& Walker, R. (2005). Protective orders in rural and urban areas: A multiple perspective study. Violence Against Women, 11(7), 876-911.

Mears, D. P. (2003). Research and interventions to reduce domestic violence revictimization. Trauma, Violence, \& Abuse, 4(2), 127-147.

Moffitt, T. E., Caspi, A., Rutter, M., \& Silva, P. A. (2001). Sex differences in antisocial behavior: Conduct disorder, delinquency, and violence in the Dunedin longitudinal study. Cambridge, UK: Cambridge University Press.

Pavlou, M., \& Knowles, A. (2001). Domestic violence: Attributions, recommended punishments, and reporting behaviour related to provocation by the victim. Psychiatry, Psychology, and Law, 8(1), 76-85.

Reddy, P., Knowles, A., Mulvany, J., McMahon, M., \& Freckelton, I. (1997). Attributions about domestic violence: A study of community attitudes. Psychiatry, Psychology, and Law, 4(2), $125-145$.

Saltzman, L. E., Fanslow, J. L., McMahon, P. M., \& Shelley, G. A. (2002). Intimate partner violence surveillance: Uniform definitions and recommended data elements, Version 1.0. Atlanta, GA: Centers for Disease Control and Prevention, National Centre for Injury Prevention and Control.

Simon, T. R., Anderson, M., Thompson, M. P., Crosby, A. E., Shelley, G., \& Sacks, J. J. (2001). Attitudinal acceptance of intimate partner violence among U.S. adults. Violence and Victims, 16(2), 115-126. 
Sorenson, S. B., \& Taylor, C. A. (2005). Female aggression toward male intimate partners: An examination of social norms in a community-based sample. Psychology of Women Quarterly, 29(1), 78-96.

Stewart, A., \& Maddren, K. (1997). Police offcers' judgements of blame in family violence: The impact of gender and alcohol. Sex Roles, 37(11/12), 921-933.

Taylor, N., \& Mouzous, M. (2006). Community attitudes to violence against women survey 2006: A full technical report. Canberra: Australian Institute of Criminology.

Walker, R., Logan, T. K., Jordan, C. E., \& Campbell, J. C. (2004). An integrative review of separation in the context of victimization: Consequences and implications for women. Trauma, Violence, \& Abuse, 5(2), 143-193.

Weiner, B. (1979). A theory of motivation for some classroom experiences. Journal of Educational Psychology, 71(1), 3-25.

Acknowledgments. This research was supported by a Griffith University New Researcher Grant. We would like to thank Professor Anna Stewart for her comments on the vignette design and Storm Cory for her work on the data collection.

Correspondence regarding this article should be directed to Susan M. Dennison, PhD, School of Criminology and Criminal Justice, Mt. Gravatt Campus, Griffith University, Brisbane, Queensland 4111, Australia. E-mail: Susan.Dennison@griffith.edu.au 